\title{
Assessment of Groundwater Pollution Potential of the Datong Basin, Northern China
}

\author{
Mamadou SAMAKE(Corrsponding author), Zhonghua Tang, Win Hlaing, Innocent M'Bue \& Kanyamanda \\ Kasereka
}

Key Laboratory of Biogeology and Environmental Geology of Ministry of Education, School of Environmental Sciences, China University of Geosciences (CUG), Wuhan 388 Lumo Road, Hubei 430074, China

E-mail: sitsam2003@yahoo.fr

Key Laboratory of Biogeology and Environmental Geology of Ministry of Education, School of Environmental Sciences, China University of Geosciences (CUG), Wuhan 388 Lumo Road, Hubei 430074, China

\begin{abstract}
Groundwater is water present below the surface of the earth in underground streams and aquifers. It is the main source of water supply in arid and semi-arid regions of northwestern China. Studies, in recent years have reported increased cases of aquifer contamination due to different factors such as rapid urbanization and industrialization. Using DRASTIC model, this study attempts to measure vulnerability of ground water to contamination in the Datong Basin, located in Northern China. To reduce subjectivity, a sensitivity analysis was performed to evaluate the influence of a single parameter on aquifer vulnerability.

The results show that $32.5 \%$ of the total study area is under a "highly vulnerable zone". In addition the most sensitive parameter to contamination is aquifer media (A), followed in importance by hydraulic conductivity (C), topography (T), depth to water (D), soil media (S), and impact of vadose zone (I). Net recharge (R) is the least sensitive parameter to pollution. Aquifer vulnerability maps developed in this study are valuable tools for environmental planning and predictive groundwater management.
\end{abstract}

Keywords: Groundwater vulnerability, DRASTIC, GIS, Sensitivity analysis

\section{Introduction}

Groundwater is the most important source of water supply in arid and semi-arid regions of northwestern China. In recent years, the use of groundwater for water supply in the area has been limited by increasing aquifer contamination. In the northern part of the Datong Basin, overuse of groundwater resources and discharge of industrial and municipal wastewater have lowered groundwater levels and worsened its quality (Guo and Wang, 2004; Wang et al., 2001). In the southern area, under natural conditions intensive evaporation, related to high groundwater levels and arid and semi-arid climate, has resulted in severe salinization and high total dissolve solids (TDS) in the groundwater. The abnormally high arsenic and fluoride concentrations in the groundwater were related to geo-environmental sources in the southern Datong Basin (Wang, 1998; Wang et al., 1998; Li, 2001). Long-term intake of the high arsenic groundwater has caused waterborne arsenic poisoning. Therefore, management of the drinking water resource and strategies for protecting its quality are essential in order to increase efficient use of existing water supplies.

In recognition of the need for effective and efficient methods for protecting ground water resources from future contamination, scientists and water resource managers have sought to develop techniques for predicting which areas are most likely to become contaminated as a result of human activities at or near the land surface (NRC, 1993). This concept has been widely termed as "groundwater vulnerability to contamination". Sensitivity of groundwater quality to an imposed contaminant load is determined by the intrinsic characteristics of the aquifer.

Recognition of groundwater vulnerability to pollution will enable the protection of groundwater sources and the management of groundwater quality conflicts. Groundwater monitoring and mathematical modeling are costly in a regional scale vulnerability assessment. Therefore, subjective modeling is required to assess the potential of groundwater contamination by nonpoint sources over large geographical areas involving a variety of hydro-geological settings.

Different models found in the literature, such as DRASTIC (Aller et al., 1987), SINTACS (Vrba and Zaporotec, 1994), EPIK technique (Doerfliger and Zwahlen, 1997), can be applied to "map" groundwater vulnerability, but application is obviously dependant on the nature and type of aquifer (El-Naqa, 2004). One of the most widely used standard groundwater vulnerability methods is DRASTIC, developed by the United States Environmental Protection Agency (USEPA) as a method for assessing groundwater pollution potential. The DRASTIC model is based on seven parameters which form the acronymic of the model.

In assessing groundwater vulnerability using overlay and index methods subjectivity is, to some extent, unavoidable through the selection of rating values and weights (Gogu and Dassargues, 2000). 
The objective of this paper is to incorporate the major hydro-geological factors that control and affect groundwater pollution potential using the DRASTIC model with modified ranking factors to reflect the unique hydro-geologic and terrain characteristics of Datong Basin in northern China. Moreover, a GIS tool has been used to create a groundwater vulnerability map, which reflects the pollution potential for the aquifer. This technology involves overlying different map layers to assess the relationship between the groundwater vulnerability map and Arsenic concentration in the groundwater.

\section{Materials and Research Methods}

\subsection{Location}

The Datong Basin $\left(112^{\circ} 13^{\prime} 37.87^{\prime \prime} \mathrm{E}, 39^{\circ} 16^{\prime} 13.025^{\prime \prime} \mathrm{N}\right.$ to $\left.112^{\circ} 0^{\prime} 15.654^{\prime \prime} \mathrm{E}, 39^{\circ} 58^{\prime} 49.064^{\prime \prime} \mathrm{S}\right)$ is a part of Shanxi Province in northern China. The study area is located in the East Asia monsoon region, with a semi-arid climate. Average precipitation is between $225 \mathrm{~mm}$ and $400 \mathrm{~mm}$ (mostly in July and August) and the yearly average air temperature is $6.5^{\circ} \mathrm{C}$.

The Datong Basin covers an area of approximately $60000 \mathrm{~km}^{2}$. It is one of the Cenozoic basins of the Shanxi rift system (Wang and Shpeyzer, 2000). Datong Basin is surrounded by undulating mountains and the topography slopes down from northwest to southeast as shown in Fig.1a.

The rivers in the area are ephemeral. Sanggan River runs across from south to north. Bedrock around the Datong Basin mainly occurs in the north, west and east of the study area. Archean gneiss and basalt outcrop in the north, Cambrian-Ordovician limestone and Carboniferous-Permian-Jurassic sandstone and shale in the west, and Archean gneiss and granite sporadically occur in the northeast (see Fig.1b) (Wang et al., 2008). Cenozoic sediments, with thicknesses up to $2500 \mathrm{~m}$, are accumulated in the basin. Shallow groundwater mainly occurs in the Quaternary alluvial, alluvial-pluvial and alluvial-lacustrine aquifers. The thickness of the Quaternary sediment gradually increases from the margin to the center of the basin, ranging from 200 to $2700 \mathrm{~m}$ in the middle of the basin. The grain size of the sediment generally decreases from the margin to the center of the basin.

\subsection{Groundwater Condition}

Shallow groundwater mainly occurs $5-80 \mathrm{~m}$ below the surface. Groundwater is recharged by infiltration (meteoric water), lateral flow groundwater from bedrocks along the mountain front, and by leakage from non-perennial rivers and irrigation tailings. Evapotranspiration and artificial abstraction are the major processes of shallow groundwater discharge. The general direction of groundwater flow is from the margin to the center of the basin.

\subsection{Methodology}

The overlay index procedure used for creating the vulnerability maps of Datong Basin is akin to the widely used DRASTIC groundwater pollution assessment method. The assessment utilizes seven hydro-geological parameters to create a final index in the framework of GIS. The DRASTIC model computes the final pollution potential index by summing the products of the ratings and weights for each of the seven factors.

$P P I=D_{\mathrm{r}} D_{\mathrm{w}}+R_{\mathrm{r}} R_{\mathrm{w}}+A_{\mathrm{r}} A_{\mathrm{w}}+S_{\mathrm{r}} S_{\mathrm{w}}+T_{\mathrm{r}} T_{\mathrm{w}}+I_{\mathrm{r}} I_{\mathrm{w}}+C_{\mathrm{r}} C_{\mathrm{w}}$

The DRASTIC acronym stands for the seven hydro-geological parameters used to determine the vulnerability of groundwater to potential contamination:

$\mathbf{D}=$ Depth to groundwater

$\mathbf{R}=$ Net Recharge

$\mathbf{A}=$ Aquifer media

$\mathbf{S}=$ Soil media

$\mathbf{T}=$ Topography

$\mathbf{I}=$ Impact of the vadose zone

$\mathbf{C}=$ Hydraulic conductivity of the aquifer.

The subscripts $\mathbf{r}$ and $\mathbf{w}$ denote the rating and the weight, respectively. Weights defined by the DRASTIC system are used for each layer to account for different land uses and to give emphasis to some layers more than others. For example, depth to groundwater is weighted as five and topography is weighted as a one, as shown as Table 1. These weightings imply that depth to groundwater is five times more important than slope for predicting aquifer sensitivity to pollution (Hamerlinck and Ameson, 1998).

Groundwater vulnerability mapping procedures were carried out in this study to incorporate the use of a GIS. A GIS is a computerized mapping and spatial data analysis system, which enables the development and analysis of spatially referenced information to describe the relationship between landscape features.

Initially, all the seven DRASTIC maps were geo-referenced, digitized, and edited to generate polygon maps. These polygon maps were classified either into ranges or into significant media types, which have an impact on pollution potential. The range for each factor has been assigned a subjective rating, which varies between 1 and 
10. The ratings are incorporated into the GIS attribute table of specific polygon maps. The polygon maps containing the rating values were then converted into specific raster maps. Weight multipliers were then used for each raster map to balance and enhance its importance. By combining all the raster maps using the above equation, a final vulnerability map was generated.

\subsection{Data preparation}

To carry out the aquifer vulnerability analysis using DRASTIC, seven thematic maps were prepared. They are as follows:

2.4.1 The Depth to water table: Depth to groundwater data were collected from borehole log information, direct measurement of water level of existing shallow tubes, and dug wells from ground surface. The inverse distance moving average interpolation technique was performed on the measured depth to groundwater point data using a simple inverse power with a limiting search distance of $7000 \mathrm{~m}$ to ensure accuracy including a high number of input points to generate a smooth surface. Assigning sensitivity rating values such as 10 for depth $(<1.5 \mathrm{~m}), 9$ for depth (1.5-4.6 m), 7 for depth (4.6-9.1 m), 5 for depth (9.1-15.2), 3 for depth (15.2-22.5 m), 2 for depth $(22.5-30 \mathrm{~m})$ and 1 for depth ( $>30 \mathrm{~m}$ and the region having no data), a depth to groundwater map was generated as shown in Fig. 2.

2.4.2 The Recharge: The net recharge is the amount of water from precipitation and artificial sources available to migrate down to the groundwater. Therefore, it is a significant vehicle for percolating and transporting contaminants to the saturated zone and also increases the water table. The shallow aquifer of the Basin is characterized by a high recharge rate but limited groundwater recharge into the deep aquifer due to an impermeable clay layer. The shallow aquifer recharge is mainly by direct infiltration from precipitation; therefore, the recharge map was constructed from the rainfall data according to the following formula:

Net recharge $=($ rainfall - evaporation $) \times$ recharge rate

The rainfall map was obtained by interpolating a forty year mean of annual precipitation (mm/year) from four representative rainfall stations (Datong, Huairen, Shuozhou and Shanyin). The recharge map was then classified into ranges and assigned ratings from 1 to 6 . High recharge rates were assigned high numerical rates.

2.4.3 The Aquifer media: It refers to the consolidated and unconsolidated rock which serves as a water storage (Chandrashekhar et al., 1999). The aquifer is defined as a rock formation which can yield sufficient quantities of water for use (Anwar et al., 2003). The shallow aquifers occur within a depth of 50m from the earth's surface. An aquifer media map was prepared from the well log data and topographical maps. The contaminant attenuation of the aquifer depends on the amount and sorting of fine grains. In general, the larger the grain-size and the more fractures or openings within the aquifers the higher the permeability and lower the attenuation capacity, consequently, the greater the pollution potential (Anwar et al., 2003). So the coarse (saturated or unsaturated) media was assigned a high rating value compared to the fine media as shown as Fig. 3.

2.4.4 The Soil media: In general, soil pollution potential is largely affected by the type and amount of clay present, the shrink/swell potential, and the soil grain size. The DRASTIC index includes soil ratings appropriate for the pollution potential associated with the development of secondary permeability. The characteristics of soil influence the amount of recharge infiltrating the ground surface and the amount of potential dispersion, the process of purifying contaminants. Soil cover characteristics influence the surface and downward movement of contaminants. The presence of fine grain size materials, such as clay, peat or silt, and the percentage of organic matter within the soil cover can decrease intrinsic permeability and retard or prevent contaminant migration throughout physico-chemical processes, i.e., absorption, ionic exchange, oxidation, and biodegradation.

2.4.5 The Topography: It refers to slope of an area. Areas with low slope tend to retain water for long periods of time. This allows greater infiltration or water recharge and a greater potential for contaminant migration. Areas with steep slopes, having large amounts of runoff and small amounts of infiltration, are less vulnerable to groundwater contamination. Topography will give an indication on whether a pollutant will run off or remain on the surface long enough to infiltrate into the ground water (Lynch et al., 1994).

2.4.6 The Impact of vadose zone: This parameter represents the influence of the unsaturated zone above the water table. It controls the passage and attenuation of the contaminated material into the aquifer. As the soil attenuation type is unavailable at the required scale, and it does not exist over the entire catchment, the following equation provides a vadose zone value for a particular area that is defined by these factors, and is relative to another zone within the context of the study area (Piscopo, 2001).

$I_{\mathrm{r}}=D_{\mathrm{r}}+S_{\mathrm{r}}$

In the context of Datong Basin, soil layer could be used and factored for its contribution to the vadose zone impact. Depth to water table has previously been used, but it is factored for its contribution to the vadose zone impact. Depth to the groundwater table for a shallow aquifer is less than $10 \mathrm{~m}$, so the rating factor 5 for the area with groundwater depth less than $10 \mathrm{~m}$, rating factor 2 for area having groundwater depth more than $10 \mathrm{~m}$ and rating factor 1 for the region having groundwater depth more than $30 \mathrm{~m}$ were assigned. Similarly, the rating factor 5 for very high to high permeable soil, 3 for medium to low permeable and 1 for very low permeable soil 
were used and then combined into two map layers to find a grid layer of impact on the vadose zone as shown as Fig. 4.

2.4.7 The Conductivity: Aquifer hydraulic conductivity is the ability of the aquifer formation to transmit water. It depends on the intrinsic permeability of the material and on the degree of saturation. These factors control the contaminant migration and dispersion from the injection point within the saturated zone and, consequently, the plume concentration in the aquifer. Generally, the hydraulic conductivity is measured from the field pumping test data. However, the absence of spatially complete data for hydraulic conductivity of the Basin's shallow aquifer has meant that this parameter was incorporated based on the limited information of transmissivity value.

For the shallow unconfined aquifer of average thickness $(15-20 \mathrm{~m})$, a hydraulic conductivity map was incorporated into the final DRASTIC index based on transmissivity values. Sensitivity ratings were assigned as ten for very high $\left(>450 \mathrm{~m}^{2} /\right.$ day), 8 for high $\left(300-450 \mathrm{~m}^{2} /\right.$ day $), 6$ for moderate $\left(100-300 \mathrm{~m}^{2} /\right.$ day $), 4$ for low $\left(10-100 \mathrm{~m}^{2} /\right.$ day $)$ and 1 for very low $\left(<10 \mathrm{~m}^{2} /\right.$ day) as shown as Fig. 5 . An aquifer with high conductivity is vulnerable to substantial contamination as a plume of contamination can move easily through the aquifer (Table 1). This is different from an aquifer with impermeable media which can still conduct water in the presence of fractures (Fritch et al., 2000).

Finally, the groundwater pollution potential index was determined by multiplying each map layer by its corresponding weighting factor elected by the DRASTIC method and by cumulating the seven individual rating maps to generate a ground water vulnerability map as shown in Fig. 6 . The resulting range of groundwater pollution potential index rating values extended from 44 to 162 , with the lowest possible rating being 44 and the highest rating being 162. These values were reclassified into three classes using the quantile classification scheme i.e., low vulnerable zones, moderate vulnerable zones and high vulnerable zones (Table 2).

\section{Sensitivity analysis}

Sensitivity analysis provides valuable information on the influence of rating values and weights assigned to each parameter (Gogu and Dassargues, 2000). The sensitivity analysis has been performed to evaluate the sensitivity of each parameter between map layers so that subjectivity can be reduced. Similar analyses have been applied in the assessment of aquifer vulnerability in different overlay techniques (Napolitano and Fabbri, 1996; Gogu and Dassargues, 2000) and Lodwik et al. 1990) to define the map-removal sensitivity measure that represents the sensitivity associated with removing one or more maps. This measure can be expressed as:

$S_{i}=\left[\frac{V_{i}}{N}-\frac{V_{x i}}{n}\right]$

where $\mathrm{Si}$ is sensitivity (for the ith unique condition subarea) associated with the removal of one map (of parameter $\mathrm{X}$ ); Vi is the vulnerability index computed using Eq. (1) on the subarea; Vxi is the vulnerability index of the subarea excluding one map layer; $\mathrm{N}$ is the number of map layers used to compute the vulnerability index in Eq. (1), and $\mathrm{n}$ is the number of map layers used for sensitivity analysis.

In order to assess the magnitude of the variation created by removal of one parameter, the variation index was computed as:

$$
V_{a r i}=\left[\frac{V_{i}-V_{x i}}{V_{i}}\right] \times 100
$$

Where $V_{\text {ari }}$ is the Variation index of the removal parameter and $V_{\mathrm{i}}$ and $V_{\mathrm{xi}}$ are vulnerability indices computed using Eq. (1) on the subarea and the vulnerability index of the subarea excluding one map layer, respectively. This variation index measures the effect of the removal of each parameter. Its value can be positive or negative, depending on the vulnerability index. Variation index directly depends upon the weighting system. Each parameter contributes with an effective weight (Napolitano and Fabbri, 1996) to the vulnerability index. This effective weight can be computed for each subarea as:

$W_{x i}=\frac{X_{r i} X_{w i}}{V_{i}} \times 100$

Where $X_{\mathrm{ri}}$ and $X_{\mathrm{wi}}$ are the rating values and the weights for the parameter $\mathrm{X}$ assigned in subarea, respectively, and $V_{\mathrm{i}}$ is the vulnerability index calculated in Eq. (1) in the subarea. The expression to compute an effective weight is apparently different from the variability index given in Eq. (5) proposed by Lodwik et al. (1990), but they are equivalent (Ramos-Leal and Rodriguez-Castillo, 2003).

\section{1 Sensitivity analysis of the DRASTIC model}

Table 3 presents a statistical summary of the seven rated parameters of the DRASTIC model used to determine the vulnerability of groundwater in the Datong Basin. An examination of the means of the parameters reveals that the highest contribution to the vulnerability index is made by aquifer media (mean $=8.526$ ). The second greatest factor is topography (mean $=4.973)$, followed by soil media $($ mean $=4.534)$, which contributes moderately to the vulnerability index. Hydraulic conductivity (mean $=3.776)$, vadose zone $($ mean $=3.091$ ), depth to water $($ mean $=3.012)$ and net recharge $($ mean $=2.898)$ contribute the least to the contamination of 
groundwater. The coefficient of variations indicates that a high contribution to the variation of the vulnerability index is made by net recharge $(94.61 \%)$ and depth to water $(94.32 \%)$ followed by hydraulic conductivity $(73.49 \%)$. Moderate contribution is made by soil media $(50.19 \%)$ and aquifer media $(21.68 \%)$, while the lowest contribution is made by impact of vadose zone (7.70\%) and topography $(4.81 \%)$.

In order to examine interdependence of the seven rated parameters for the DRASTIC model, twenty-one (21) Spearman's rank order correlations were computed. Note: $n(n-1) / 2$ (where $n$ is the number of parameters $=7$ ). In statistics, when $r$ is closed to 0 , the dispersion is large and the variables are uncorrelated. As the correlation is a measure of the relationship between two or more variables, the result showed that the relationship between the parameters was very poor and in some cases almost uncorrelated. Out of these 21 correlations only 19 (Table 4 ) are significant at or more than $95 \%$ level of confidence. This finding means that these seven parameters are largely independent and that there is very little risk of maladjustment in the final index.

\subsection{Map removal sensitivity analysis}

Table 5 and Table 6 show a map removal sensitivity analysis that was performed by removing one or more data layer. The study shows that there is a clear variation in vulnerability index with each removal of a layer. The map removal analysis shows that the greatest variation in the ground water vulnerability index occurs when an aquifer media layer is removed from the computation because this factor's mean variation index is $(6.89 \%)$. This can be due to the high theoretical weight assigned to the net recharge parameter. Furthermore, the vulnerability index seems to be sensitive to the removal of the hydraulic conductivity layer as its mean variation index is $5.80 \%$. Removal of the topography layer also bears considerably on the variation of the vulnerability index to its high mean variation index (4.81\%). Removal of the depth to water mean variation index $4.50 \%$ has also contributed significantly to the variation in the groundwater vulnerability index. The least sensitive parameters are soil media, vadose zone and net recharge (respective mean variation indices are $3.86 \%, 3.26 \%$ and $2.33 \%$ ). Table 6 shows the variation of vulnerability index due to the removal of one data layer at a time from the DRASTIC model computation.

\subsection{Single parameter sensitivity analysis}

The significance of seven parameters for the assessment of the DRASTC groundwater vulnerability index has already been established from the previous map removal analysis. The single parameter sensitivity analysis is designed to compare their "theoretical" weights with that of "effective" weights. The effective weight is a function of value of the single parameter with regard to the other six parameters as well as the weight assigned to it by the DRASTIC model (Babiker et al., 2005). The effective weights of the DRASTIC parameters exhibited some deviation from those of the theoretical weights. Table 7 reveals that the aquifer media and hydraulic conductivity layer tend to be the most effective parameters in the vulnerability assessment because their mean effective weights, $20.56 \%$ and $20.04 \%$, respectively, are higher than their respective theoretical weights. Mean effective weight of depth to water, soil media and topography $20.54 \%, 8.01 \%$ and 5.14 respectively, were almost equal to their respective theoretical weight. Impact of vadose zone shows a low effective weight when compared with the theoretical weight. The lowest effective weight was net recharge $(9.09 \%)$ compared to its theoretical weight $(17.39 \%)$. This shows the importance of aquifer media and hydraulic conductivity layers in the DRASTIC model. In this case study, the calculated effective weights for each parameter are not closely equal to the theoretical weights assigned in DRASTIC method due to the fact that weight factors are strongly related to the value of a single parameter in the context of value chosen for the other parameters. Therefore, the effective weights analysis is very useful to revise the weight factors such that the DRASTIC method may be applied more scientifically to address local issues and represent the local hydro-geological settings.

\subsection{Ground water contamination analysis}

The purpose of this analysis is to assess the relationship between the groundwater vulnerability map and Arsenic concentration in groundwater. The concentrations of arsenic have been shown in Fig. 7 and Fig. 8. These sampled well maps were overlaid on the vulnerability map (Fig. 9) in order to see how many wells with a high concentration of arsenic are found in different vulnerability zones. Among 145 wells, about 25 wells with a high concentration of arsenic are located in the high vulnerable zones, and 51 wells with a low concentration of arsenic are located in the high vulnerable zones. In addition, one well which has a high concentration of arsenic is located in the moderate vulnerable zone and one well which has a high concentration of arsenic is located in the low vulnerable zone. The rest (46 wells and 21 wells) which have lower concentrations of arsenic are respectively located in moderate and low vulnerable zones. These findings supplement the results obtained by the DRASTIC model.

The sensitivity operation has been carried out by using the present arsenic concentration within the block by cross operation under the GIS platform. Three classes have been attributed to the arsenic distribution. They are low $(<0.05 \mathrm{mg} / \mathrm{l})$, medium $(0.05-0.1 \mathrm{mg} / \mathrm{l})$ and high $(>0.1)$. In the next step, the vulnerability map and the arsenic zone map have been crossed to generate two maps. Figure 10 shows the areas where the various vulnerability classes have matched with the arsenic distribution. They cover 397510 hectare, which is $57 \%$ of the total block area. In the rest of the area (high vulnerability * low arsenic), the present arsenic concentration 
and aquifer vulnerability do not match. Therefore, it can be said that the aquifer vulnerability analysis is more or less reliable.

\section{Results and discussion}

The results of this study show that, of the total 696187 hectares, an area of about 164307 hectares is in the low vulnerable zone with a DRASTIC index range between 44 and 85. An additional 305609 hectares are in the moderately vulnerable zone with a DRASTIC index ranging between 86 and 111. And, about 226270 hectares are in the high vulnerability zone with a DRASTIC index ranging between 112 and 162 . This means that nearly one third of the Datong Basin groundwater is at high risk in terms of pollution potential.

These areas are mainly in the central parts of the basin where the physical factors such as gentle slope and high water table significantly affect the chances of having shallow aquifer water polluted. The areas designated as high vulnerable pollution are mainly the ancient geological forms i.e., central, south and southwest of Huairen, Shanyin, Shuozhou City. The ground water pollution potential index is directly proportional to the relative pollution potential. The sites with highest category are those more vulnerable to contamination and, consequently, need to be managed efficiently.

The sensitivity analysis which was carried out in this study helps to validate and evaluate the consistency of the analytical results and is the basis for proper evaluation of vulnerability maps. Using sensitivity analysis, a more efficient interpretation of the vulnerability index can be achieved. The statistical analysis shown in Table 5 confirms parameter A is most sensitive to contamination, followed in importance by parameters C, T, D, S, I and $\mathrm{R}$. The study shows that $32.5 \%$ of the total study area is under the high vulnerable zone, which is mainly the result of the aquifer media of Datong Basin and its surrounding areas. About 23.6\% of the area is under the low vulnerable zone. The study also shows that, with the help of GIS software, once the different data layers are prepared and overlaid, the water vulnerable zones can easily be identified. Sensitivity analysis reveals that in $57 \%$ of the area vulnerability matches with the arsenic distribution.

This study produced a very valuable tool for those who are in management positions because it gives a very comprehensive indication of vulnerability to GW contamination. The high vulnerability of GW contamination makes it absolutely necessary for local authorities who manage GW resources, to monitor this problem closely and to act accordingly. Apart from GW vulnerability assessment, the DRASTIC model can be used for wide ranging of applications. Among other uses, it can help the planner and policy maker when selecting areas for waste disposal and industrial sites.

\section{Acknowledgments}

The author is thankful to Chinese Scholarship Council (CSC), China University of Geosciences (CUG) for their financial support. Special thanks go to Prof. Tang Zhonghua for his guidance during the researches and to Mr. Gary Reece who despite his multitude occupations have accepted to read the manuscript.

\section{References}

Aller L, Bennet T, Lehr HJ, Petty JR, Hackett G, DRASTIC. (1987). a standardized system for evaluating groundwater pollution potential using hydrogeologic settings. EPA-600/2-87-035, 1987. 622.

Anwar, Prem, \& Rao , M. Anwar, C.C. Prem and V.B. Rao. (2002). Evaluation of groundwater potential of Musi River catchment using DRASTIC index model. In: B.R. Venkateshwar, M.K. Ram, C.S. Sarala and C. Raju, Editors, Hydrology and watershed management. Proceedings of the international conference 18-20, 2002, B. S. Publishers, Hyderabad (2003), pp. 399-409.

Babiker IS, Mohammed MAA, Hiyama T, \& Kato K. (2005). A GIS-based DRATIC model for assessing aquifer vulnerability in Kakamigahara Heights, Gifu Prefecture, central Japan. Sci Total Environ 2005; 345: 127-140.

Chandrashekhar H, Adiga S, Lakshminarayana V, Jagdeesha CJ, Nataraju C. (1999). A case study using the model 'DRASTIC' for assessment of groundwater pollution potential. In Proceedings of the ISRS national symposium on remote sensing applications for natural resources. June, 1999: 19-21, Bagalore.

Doerfliger N, Zwahlen F. EPIK. (1997). A new method for outling of protection areas in karstic environment. In: International symposium on karst waters and environmental impacts, 1997:117-123.

El-Naqa A. (2004). Aquifer vulnerability assessment using the DRASTIC model at Russeifa landfill, northeast Jordan. J Environ Geol 2004:47(1):51-62.

Fritch TG, McKnight CL, Yelderman Jr JC, \& Arnold JG. (2000). An aquifer vulnerability assessment of the paluxy aquifer, central Texas, USA, using GIS and a modified DRASTIC approach. Environ Manage 2000; 25:337-345.

Gogu RC, Dassargues A. (2000). Sensitivity analysis for the EPIK method of vulnerability assessment in a small karstic aquifer, Southern Belgium. Hydrogeol J 2000; 8(3):337-345.

Guo H, Wang Y. (2004). Specific vulnerability assessment using the MLPI model in Datong city, Shanxi province, China. Environ Geol; 45:401-407. 
Hamerlinck JD, Ameson CS. (1998). (eds) Wyoming Groundwater vulnerability assessment handbook, Vol I. University of Wyoming, SDVC Report, 98-01-1, pp 31-62.

Li YM. (2001). Environmental chemistry study of waterborne poisoning in Shanyin, Shanxi province. MS. Thesis, China University of Geosciences, Wuhan, P.R. China (In Chinese, with English Abstract).

Lodwik WA, Monson W, Svoboda L. (1990). Attribute error and sensitivity analysis of maps operation in geographical information systems-suitability analysis. Int J Geograph Inf Syst; 4:413-428.

Lynch SD, Reynders AG, \& Schulze RE. (1994). Preparing input data for a national-scale groundwater vulnerability map of southern Africa. Document ESRI 94.

Merchant JW. (1994). GIS-based groundwater Pollution hazard assessment a critical review of the DRASTIC model. Photogramm Eng Rem S; 60(9):1117-1127.

Napolitano P, Fabbri AG. (1996). Single parameter sensitivity analysis for aquifer vulnerability assessment using DRASTIC and SINTACS. In: Proceedings of the 2nd HydroGIS conference. IAHS Publication, Wallingford; 235:559-566.

National Research Council Groundwater vulnerability assessment. (1993). Contamination potential under conditions of uncertainty, National Academy Press, Washington, DC.

Piscopo, G. (2001). Groundwater Vulnerability Map Explanatory Notes - Castlereagh Catchment. Parramatta NSW: Australia NSW Department of Land and Water Conservation.

Ramos-Leal JA, Rodríguez-Castillo R. (2003). Aquifer vulnerability mapping in the Turbio river valley, Mexico, a validation study. Geofísica Int; 42(1):141-156.

Vrba J, Zaporozec A. (1994). Guidebook on mapping groundwater vulnerability, international contributions to hydrology. Heinz Heise, Hannover; 16: 131.

Wang JH. (1998). Endemic arseniasis and endemic fluorosis and regional environmental geochemical research in Datong basin, Shanxi province. PhD Thesis, China University of Geosciences, Beijing, P. R. China (In Chinese, with English Abstract).

Wang JH, Zhao LS, Wu YB. (1998). Environmental geochemical study on arsenic in arseniasis areas in Shanyin and Yingxian, Shanxi Province. Geosciences (In Chinese with English Abstract);12 (2), 243-248.

Wang Y, Ma T, Luo Z. (2001). Geostatistical and geochemical analysis of surface water leakage into groundwater on a regional scale: a case study in the Liulin karst system, northwestern China. $J$ Hydrol; 246:223-234.

Wang Y, Stepan LS, Su C. (2008). Genesis of arsenic/fluoride-enriched soda water: a case study at Datong, northern China. App Geochem. In press.

Zhang R, Hamerlinck JD, Gloss SP, Munn L. (1996). Determination of nonpoint source pollution using GIS and numerical models. J Environ Qual; 25(3):411-418. 
Table 1. DRASTIC parameters

\begin{tabular}{|c|c|c|c|c|c|}
\hline & & Ranges (m) & Rating & Index & Weight \\
\hline \multirow[t]{8}{*}{1.} & Depth to Water & $0-1.5$ & 10 & 50 & 5 \\
\hline & & $1.5-4.6$ & 9 & 45 & \\
\hline & & $4.6-9.1$ & 7 & 35 & \\
\hline & & $9.1-15.2$ & 5 & 25 & \\
\hline & & $15.2-22.5$ & 3 & 15 & \\
\hline & & $22.5-30$ & 2 & 10 & \\
\hline & & $>30$ & 1 & 5 & \\
\hline & & $(\mathrm{mm} / \mathrm{yr})$ & & & \\
\hline \multirow[t]{4}{*}{2.} & Net recharge & $0-51$ & 1 & 4 & 4 \\
\hline & & $51-76$ & 2 & 8 & \\
\hline & & $76-102$ & 4 & 16 & \\
\hline & & $>102$ & 6 & 24 & \\
\hline \multirow[t]{5}{*}{3.} & Aquifer media & fine sand & 4 & 12 & 3 \\
\hline & & medium sand & 6 & 18 & \\
\hline & & coarse sand & 8 & 24 & \\
\hline & & gravel sand & 9 & 27 & \\
\hline & & gravel & 10 & 30 & \\
\hline \multirow[t]{10}{*}{4} & Soil Media & Clay & 1 & 2 & 2 \\
\hline & & Silty clay & 2 & 4 & \\
\hline & & Silty soil & 3 & 6 & \\
\hline & & Silty sand & 4 & 8 & \\
\hline & & Find sand & 5 & 10 & \\
\hline & & Medium sand & 6 & 12 & \\
\hline & & Coarse sand & 7 & 14 & \\
\hline & & Gravel sand & 8 & 16 & \\
\hline & & Gravel & 9 & 18 & \\
\hline & & Slope Ranges (\%) & & & \\
\hline \multirow[t]{3}{*}{5} & Topography & $12-14$ & 4 & 4 & 1 \\
\hline & & $10-12$ & 5 & 5 & \\
\hline & & $8-10$ & 6 & 6 & \\
\hline \multirow[t]{8}{*}{6} & Impact of vadose & Very low permeable soil \& & & & 5 \\
\hline & zone & GW depth $>30 \mathrm{~m}$ & 1 & 5 & \\
\hline & & GW depth $>10 \mathrm{~m}$ & 2 & 10 & \\
\hline & & Medium to low permeable & & & \\
\hline & & soil & 3 & 15 & \\
\hline & & Very high to high & & & \\
\hline & & permeable soil \& GW & 5 & 25 & \\
\hline & & $\begin{array}{c}\text { depth }<10 \mathrm{~m} \\
(\mathrm{~m} / \text { day })\end{array}$ & & & \\
\hline \multirow[t]{5}{*}{7} & Hydraulic & $<10$ & 1 & 3 & 3 \\
\hline & conductivity & $10-100$ & 4 & 12 & \\
\hline & & $100-300$ & 6 & 18 & \\
\hline & & $300-450$ & 8 & 24 & \\
\hline & & $>450$ & 10 & 30 & \\
\hline
\end{tabular}

\begin{tabular}{ccccc}
\hline \multicolumn{5}{l}{ Table 2. Area under vulnerability to groundwater pollution in Datong basin } \\
\hline SN & Drastic Index & Area (Ha) & Area (\%) & Vulnerability zones \\
\hline 1 & $44-85$ & 164307 & 23.6 & Low \\
2 & $86-111$ & 305609 & 43.9 & Moderate \\
3 & $112-162$ & 226270 & 32.5 & High \\
\hline
\end{tabular}

Table 3. Statistical summary of the DRASTIC parameter map

\begin{tabular}{cccccccc}
\hline & $\mathrm{D}$ & $\mathrm{R}$ & $\mathrm{A}$ & $\mathrm{S}$ & $\mathrm{T}$ & $\mathrm{I}$ & $\mathrm{C}$ \\
\hline Min & 1 & 0 & 4 & 1 & 4 & 1 & 1 \\
Max & 10 & 6 & 10 & 9 & 6 & 5 & 10 \\
Mean & 3.012 & 2.898 & 8.526 & 4.534 & 4.973 & 3.091 & 3.776 \\
SD & 2.841 & 2.742 & 1.849 & 2.276 & 0.383 & 1.471 & 2.775 \\
CV (\%) & 94.32 & 94.61 & 21.68 & 50.19 & 4.81 & 7.70 & 73.49 \\
\hline
\end{tabular}

Coefficient of Variation - CV Standard Deviation - SD

Depth to water - D, Net recharge - R, Aquifer media - A, Soil media - S, Topography - T, Impact of vadose zone - I, and Hydraulic conductivity - C 
Table 4. Summary of rank-order correlation analysis result between seven DRASTIC parameters

\begin{tabular}{ccc}
\hline Correlated Parameters & Correlation Coefficient $\mathrm{r}$ & Significance Level P \\
\hline D \& R & 0.046 & 0.01 \\
D \& A & 0.062 & 0.01 \\
D \& S & 0.065 & 0.01 \\
D \& T & 0.410 & 0.01 \\
D \& I & 0.526 & 0.01 \\
D \& C & -0.187 & 0.01 \\
R \& A & 0.131 & 0.01 \\
R \& S & -0.042 & 0.01 \\
R \& T & 0.044 & 0.05 \\
R \& C & -0.036 & 0.01 \\
A \& S & 0.339 & 0.01 \\
A \& T & 0.205 & 0.01 \\
A \& C & 0.138 & 0.01 \\
S \& T & 0.112 & 0.01 \\
S \& I & 0.153 & 0.01 \\
S \& C & 0.067 & 0.01 \\
T \& I & 0.240 & 0.01 \\
T \& C & -0.050 & 0.01 \\
I \& C & -0.130 & 0.01 \\
\hline
\end{tabular}

Note: Only statistically significant (confidence level at or more than 95\%) inter-correlations area shown.

Depth to water - D, Net recharge - R, Aquifer media - A, Soil media - S, Topography - T, Impact of vadose zone - I, and Hydraulic conductivity - C

Table 5. Statistics of map removal sensitivity analysis

\begin{tabular}{ccccc}
\hline Parameter of Sensitivity & Minimum & Maximum & Mean & Std. Deviation \\
\hline D & 0 & 10 & 4.50 & 3.314 \\
R & 0 & 6 & 2.33 & 2.437 \\
A & 0 & 10 & 6.89 & 3.190 \\
S & 0 & 9 & 3.86 & 2.286 \\
T & 0 & 6 & 4.81 & 1.152 \\
I & 0 & 5 & 3.26 & 1.650 \\
C & 1 & 10 & 5.80 & 2.519 \\
\hline
\end{tabular}

Depth to water - D, Net recharge - R, Aquifer media - A, Soil media - S, Topography - T, Impact of vadose zone - I, and Hydraulic conductivity - C

Table 6. Statistics on sensitivity to removing one parameter

\begin{tabular}{ccccc}
\hline Parameter use & Minimum & Maximum & Mean & Std. Deviation \\
\hline D & -2.59 & 6.023 & 1.397 & 2.298 \\
R & -3.64 & 3.357 & -0.794 & 1.518 \\
A & -2.95 & 3.50 & 0.1094 & 1.346 \\
S & -2.88 & 2.023 & -0.1064 & 0.824 \\
T & -3.02 & 0.166 & -0.154 & 0.623 \\
I & -2.54 & 3.28 & 0.364 & 1.108 \\
C & -2.833 & 4.285 & 0.550 & 1.369 \\
\hline
\end{tabular}

Depth to water - D, Net recharge - R, Aquifer media - A, Soil media - S, Topography - T, Impact of vadose zone - I, and Hydraulic conductivity - C 
Table 7. Assigned weighting factor for standard DRASTIC method and statistical analysis of effective weight

\begin{tabular}{cccccc}
\hline Parameter & $\begin{array}{c}\text { Assigned } \\
\text { Weight }\end{array}$ & $\begin{array}{c}\text { Assigned } \\
\text { Weight }(\%)\end{array}$ & $\begin{array}{c}\text { Variation index } \\
\left(\approx \mathrm{W}_{\mathrm{xi}}\right)\end{array}$ & $\begin{array}{c}\text { Calculated } \\
\text { effective } \\
\text { weight after } \\
\text { rescaling }(\mathrm{X})\end{array}$ & $\begin{array}{c}\text { Calculated } \\
\text { effective } \\
\text { weight }(\%)\end{array}$ \\
\hline $\mathrm{D}$ & 5 & 21.74 & 0.285 & 4.72 & 20.54 \\
$\mathrm{R}$ & 4 & 17.39 & 0.090 & 2.09 & 9.09 \\
$\mathrm{~A}$ & 3 & 13.04 & 0.205 & 4.73 & 20.56 \\
$\mathrm{~S}$ & 2 & 8.70 & 0.080 & 1.84 & 8.01 \\
$\mathrm{~T}$ & 1 & 4.35 & 0.051 & 3.18 & 5.14 \\
$\mathrm{I}$ & 5 & 21.74 & 0.166 & 4.61 & 16.62 \\
$\mathrm{C}$ & 3 & 13.04 & 0.200 & 20.04 \\
\hline
\end{tabular}

Depth to water - D, Net recharge - R, Aquifer media - A, Soil media - S, Topography - T, Impact of vadose zone - I, and Hydraulic conductivity - C Effective weight- $\mathrm{W}_{\mathrm{xi}}$

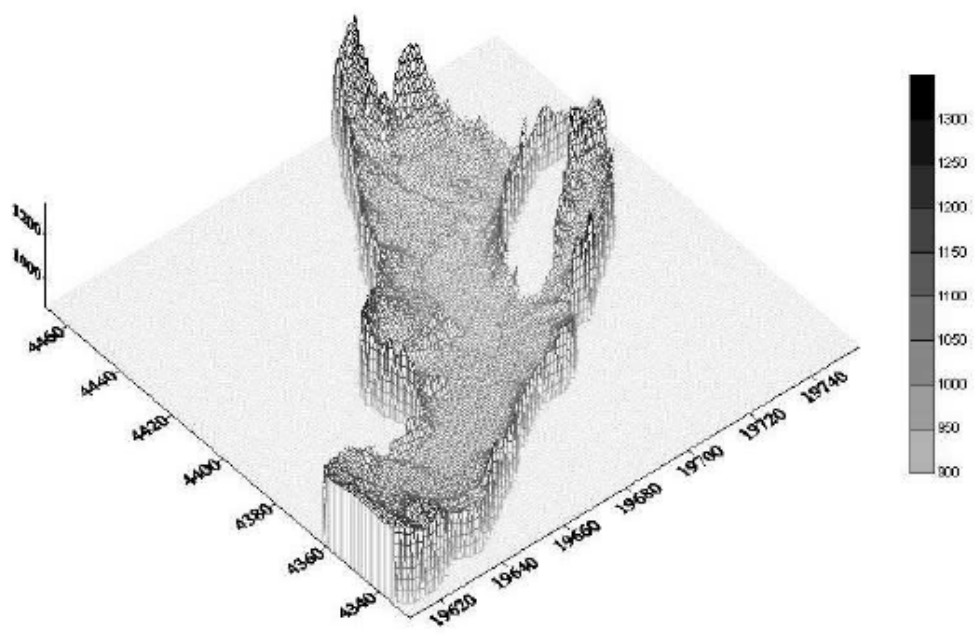

Figure 1(a) Topographic map of Datong basin

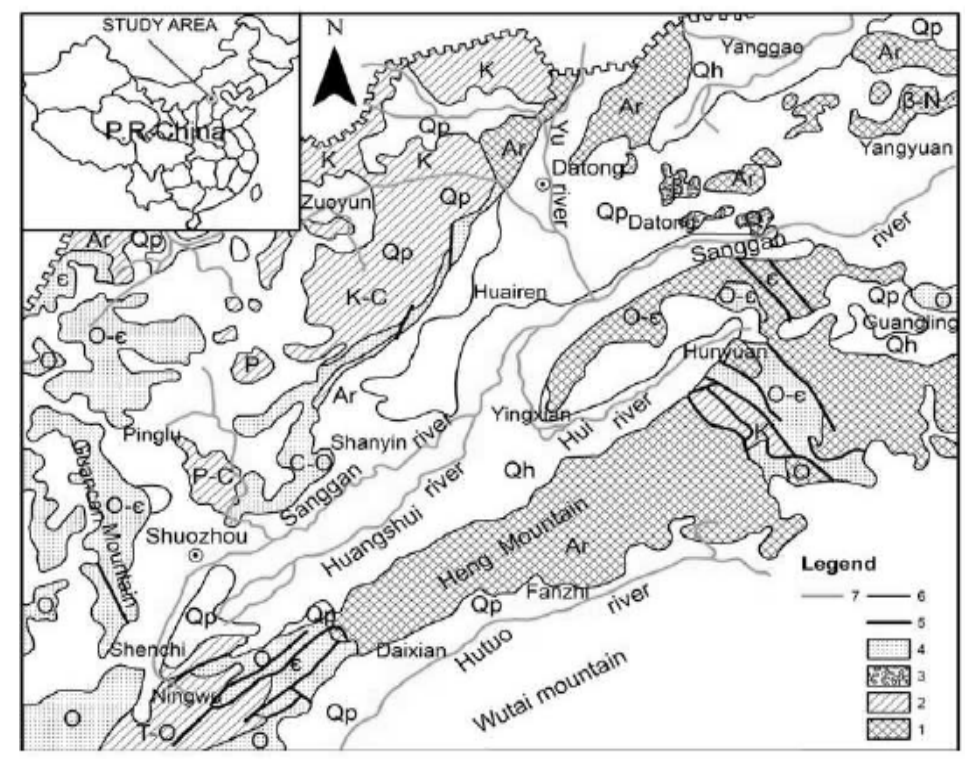

Figure 1(b) Sketch map of geology of Datong basin (wang et al., 2008). 1. Metamorphic and igneous rocks; 2. Clastic rock and coal-bearing layers; 3. Quaternary basalt; 4. carbonate rocks; 5. Faults; 6. Geologic boundary; 7. Rivers; Qh-Holocene; Qp-Pleistocene; $\beta Q$-Quaternary basalt; $\beta \mathrm{N}-$ Tertiary basalt; K-Cretaceous; P-Permian; C-Carboniferous; O-Ordovician; є-Cambrian; Ar-Archean 


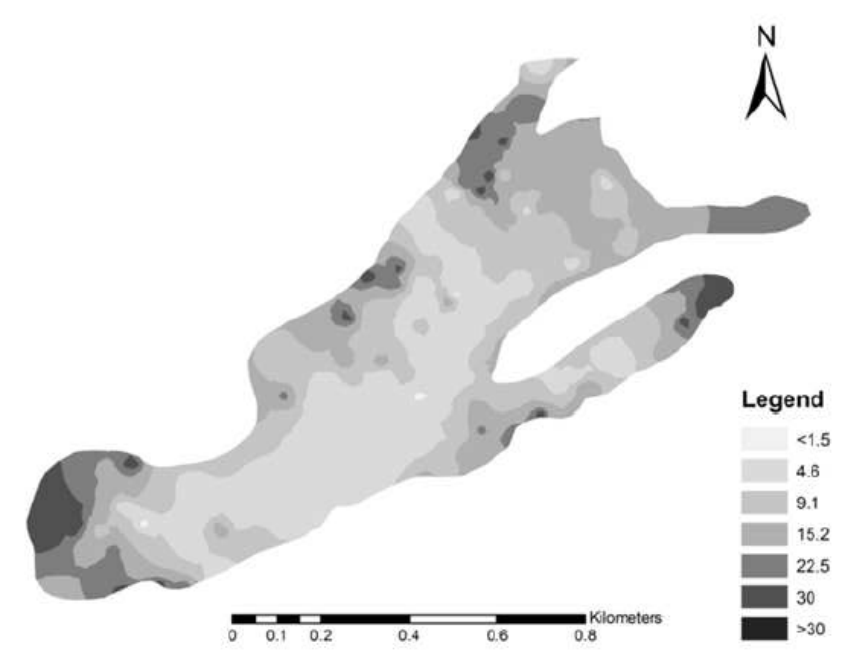

Figure 2. Depth to ground water

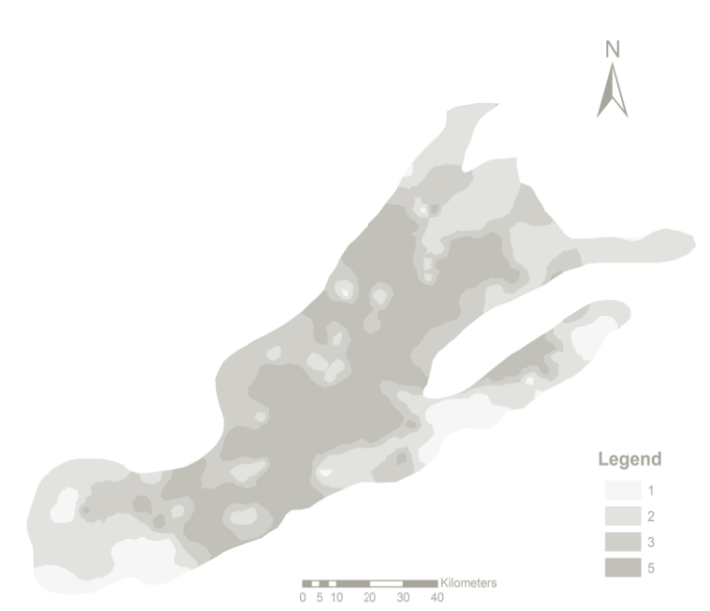

Figure 4. Impact of vadose zones

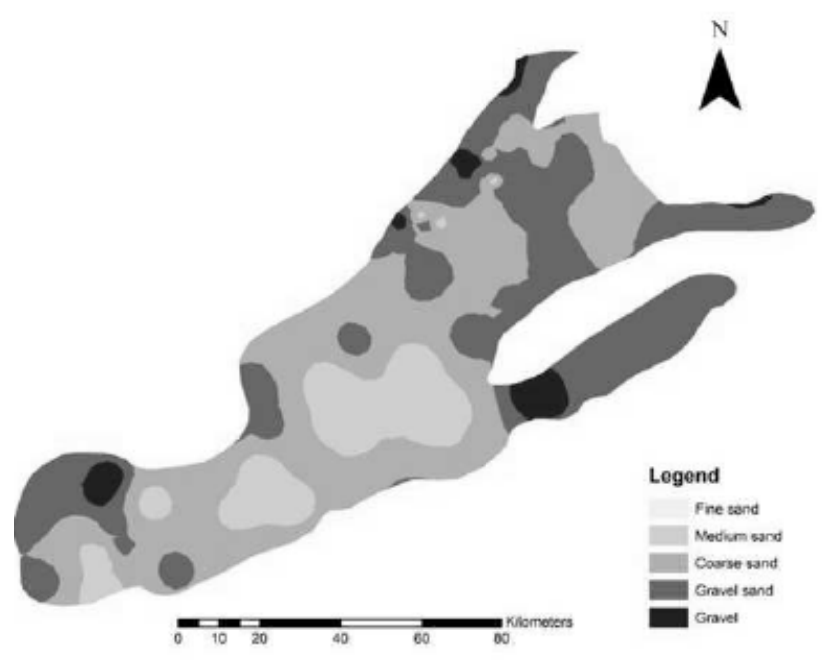

Figure 3. Aquifer media

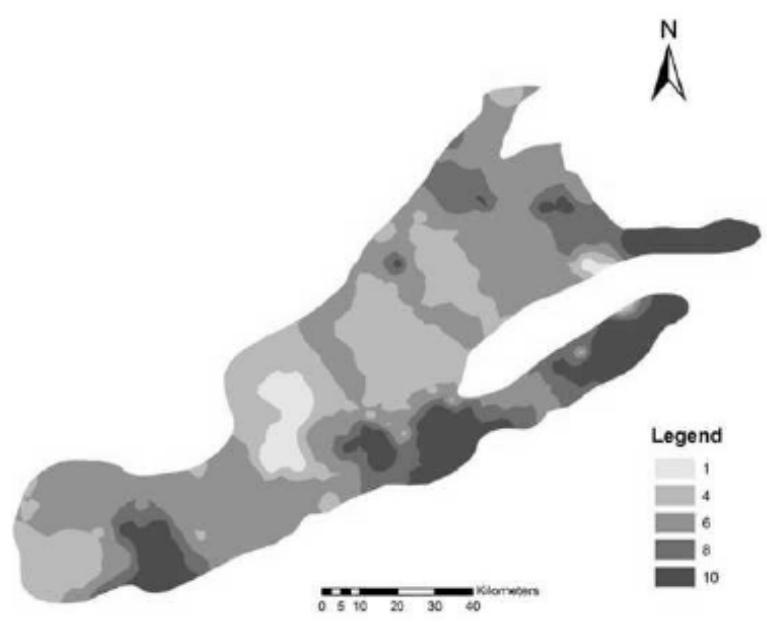

Figure 5. Hydraulic conductivity

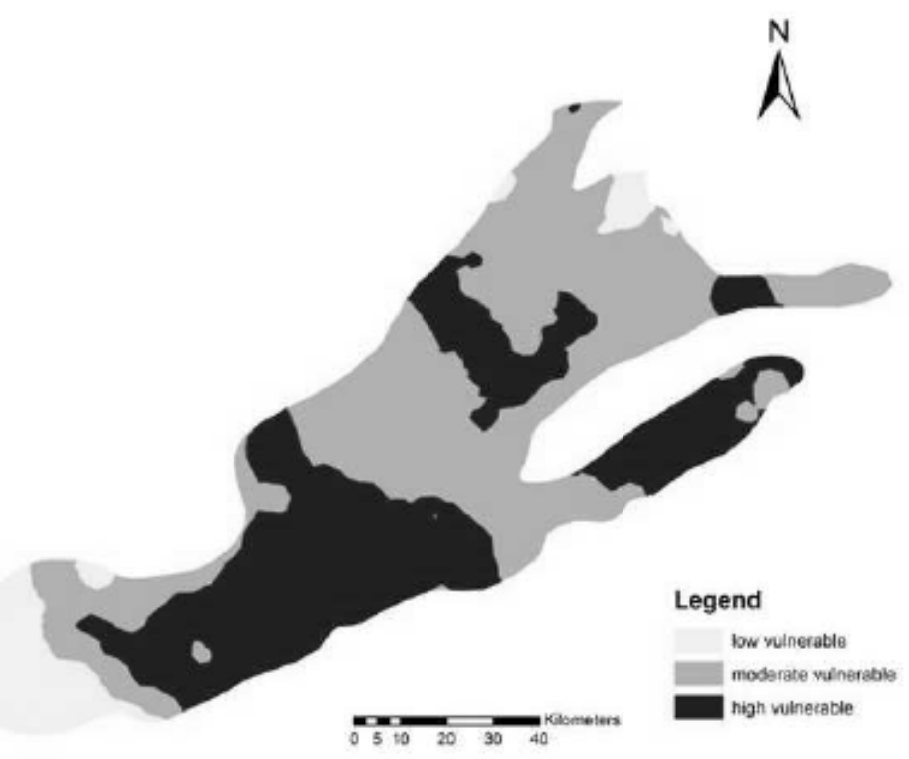

Figure 6. Groundwater vulnerable zones 


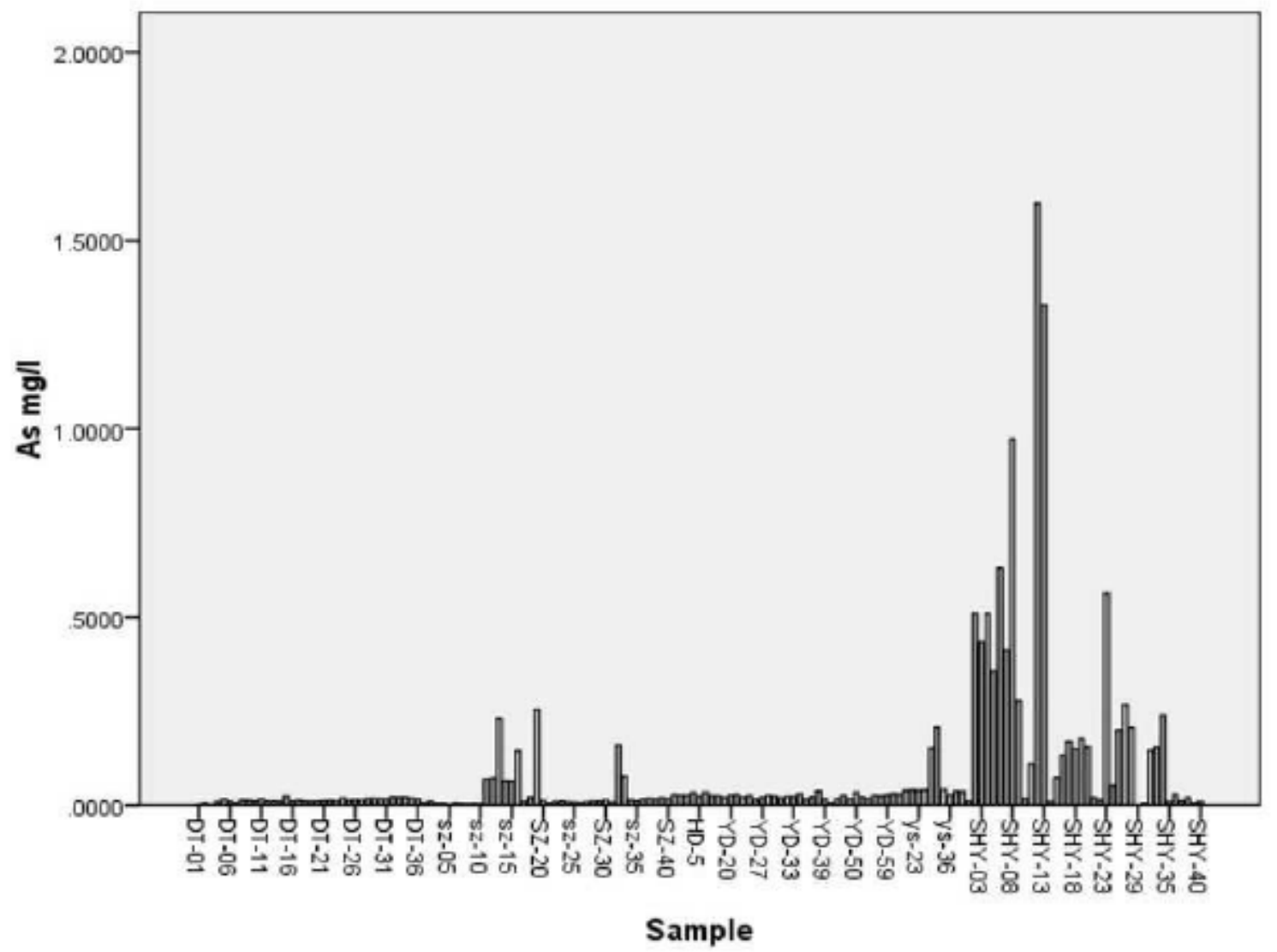

Figure 7. Arsenic concentrations in different wells

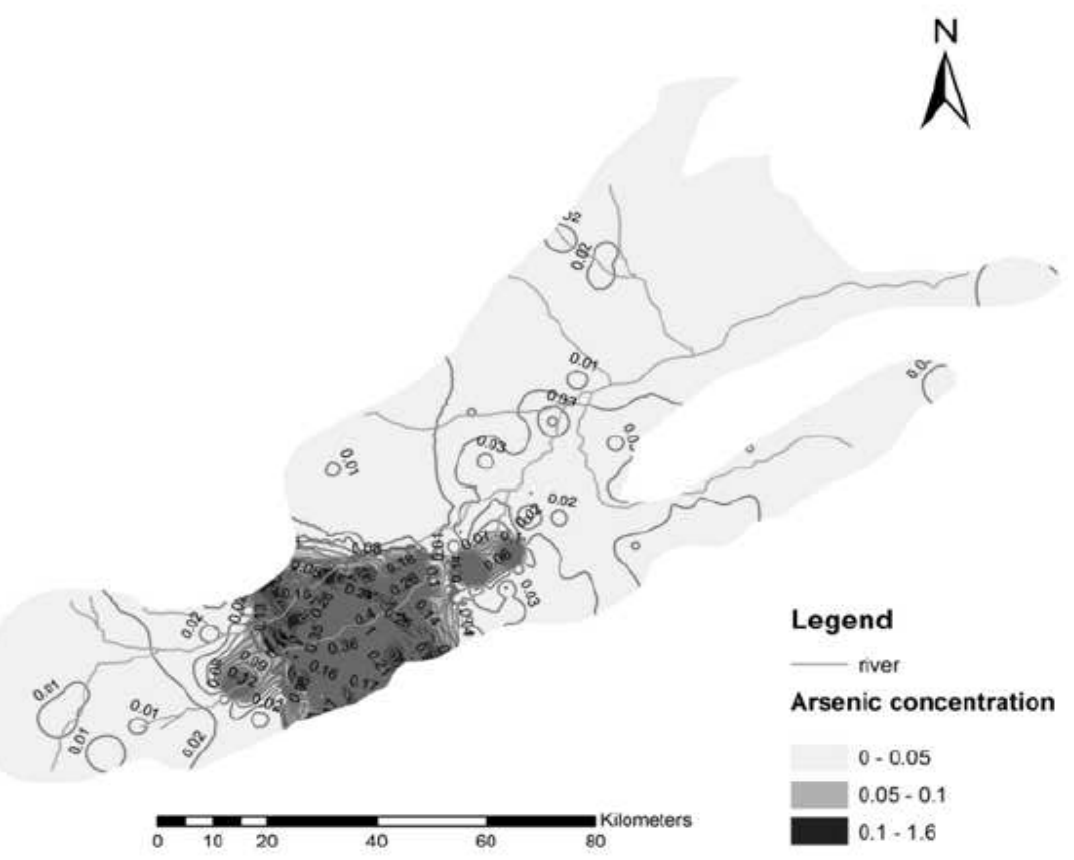

Figure 8. Arsenic concentration of Datong basin (mg/l) 


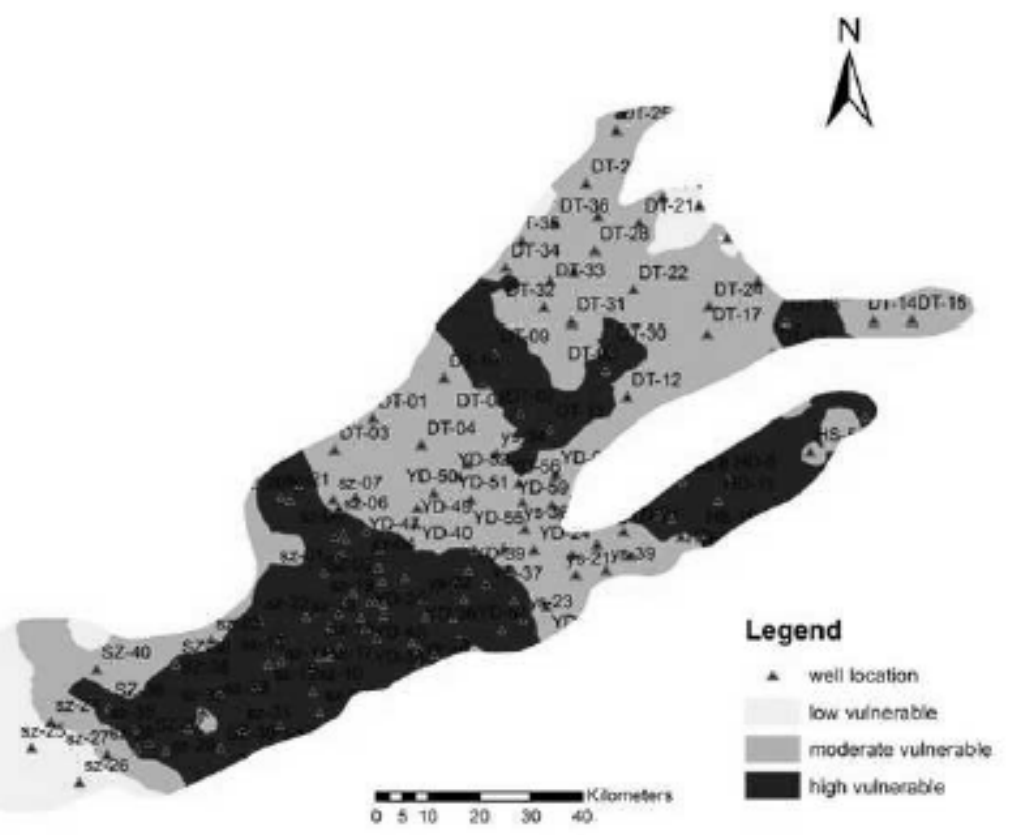

Figure 9. Vulnerable zones and well location of Datong Basin

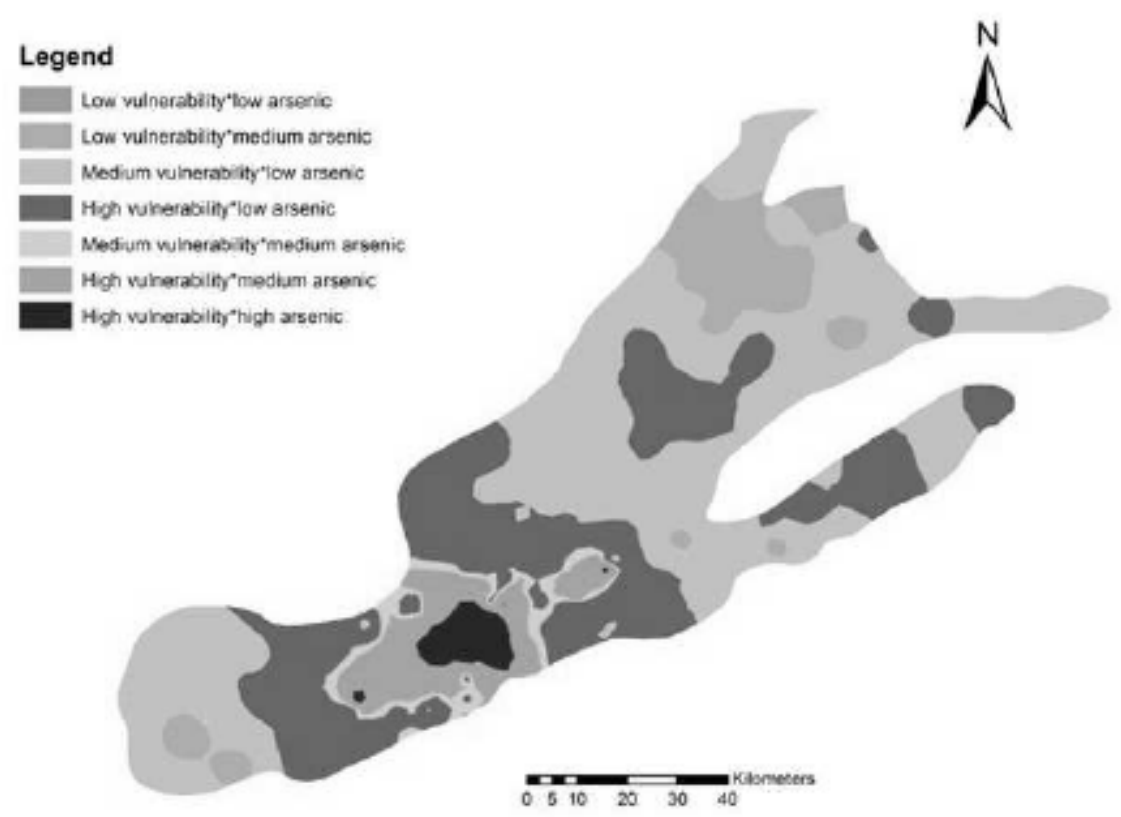

Figure 10. Cross generate two maps of the vulnerability map and the arsenic zone map 